\title{
SI NOS PERMITEN HABLAR: \\ LOS ESPACIOS SILENCIADOS Y LA DECONSTRUCCIÓN DEL DISCURSO DEL SILENCIO EN LA NARRATIVA DE LUCIA GUERRA
}

\author{
POR \\ Gloria Gálvez-Carlisle \\ University of California, Los Angeles
}

Frutos extraños (1991), la reciente colección de cuentos de Lucía Guerra, comienza con la siguiente significativa afirmación: "Atada a una estaca y con el cuerpo preñado de fantasías". Me pareció apropiado aludir a esta cita, porque, curiosamente, apunta al meollo de mi ponencia: la exploración y el tratamiento de "los espacios silenciados" y la deconstrucción del discurso del silencio en la narrativa de esta escritora chilena, específicamente en la colección de cuentos antes mencionada y en su novela Más allá de las máscaras (1984).

Como el título lo sugiere, Más allá de las máscaras osadamente pretende examinar y cuestionar los muchos y diversos aspectos de la opresión femenina "como resultado de la combinación de los accidentes de la Historia" (Cixous, The Newly Born Woman 70). Me refiero a las construcciones culturales de "lo femenino" "en la versión masculina de la realidad", aludiendo a la "dicotomía clásica del pensamiento falologocéntrico en el que Ser mujer equivale a No-Ser" (Guerra, "Las sombras de la escritura: hacia una teoría de la producción literaria de la mujer latinoamericana" 134). Consecuentemente, desenmudecer "toda una zona enraizada en la subordinación, el silenciamiento y la represión"l será la gran lucha de Cristina, la protagonista de la novela. La verdad dice Cristina es que:

estaba cansada de fingir lo que no era. En lo más profundo de mi ser, ansiaba el despojo de todas esas absurdas máscaras: la máscara del vestuario recatado, la máscara de las actitudes pudorosas, la máscara de la moralidad obsesionada por el pecado. ... empecé a

\footnotetext{
${ }^{1}$ En su artículo "Las sombras de la escritura: hacia una teoría de la producción literaria de la mujer latinoamericana", Lucía Guerra alude a las construcciones histórico-culturales de lo femenino. Si bien es cierto en la versión masculina de la realidad "Ser mujer equivale a No-Ser (pasividad, carencia de racionalidad, intuición vencida por la lógica), ... ella, en su posición marginal, [nos dice Guerra] ha sido el agente activo de una "Sub-Historia" que posee como núcleo su intervención modificadora en el espacio doméstico, los valores éticos, el consumo y la diseminación de los objetos culturales" $(134,35)$. El desenmudecer toda una zona enraizada en la subordinación, el silenciamiento y la represión hace que el texto femenino se convierta en un texto político, no sólo expresión de un grupo marginalizado, sino también, como ha postulado Hélène Cixous en The Newly Born Woman, expresión que nace "... from a violent and anguished direct refusal to accept what is happening on the stage of whose edge I find I am placed, as a result of the combined accidents of History" (70).
} 
sentirme como un mimo ingenuo que estaba representando las variaciones de un rol muy restringido y mortal de aburrido, fingiendo siempre ser lo que yo no era pero, en todo caso, me preguntaba, qué era yo, quién era ... $(15,16)$.

Lucía Guerra, haciendo eco al autoexamen de índole ontológico postmoderno, tema candente e insistentemente debatido por la crítica feminista contemporánea (Cixous, Irigaray, Showalter, Gilligan, entre otras), consecuentemente intenta, en Más allá de las máscaras, "bucear en las zonas silenciadas de ese otro Ser sitiado en el vacío y más allá de los límites asignados a un Sujeto masculino y un Otro femenino" (Guerra, "Las sombras" 141). ${ }^{2}$ En este proceso de surgimiento de la voz femenina y en un arranque de rebeldía, tratando de subvertir las reglas del juego, la protagonista atenta la igualdad con el hombre, por medio de la imitación de sus formas de conducta. Contrariamente a lo que ocurre en "Pollito Chicken" de Vega, o en las obras de otras escritoras latinoamericanas contemporáneas Solitario de amor de Peri Rossi o Vaca sagrada de Diamela Eltit-en las que la sexualidad es signo de un "Otro" subversivo, en Más allá de las máscaras no sucede lo mismo. Aunque la experiencia sexual conlleva la noción de jouissance como potencia liberadora, la protagonista descubre el vacío casi existencial que permea la relación entre hombre y mujer cuando se funda en el desamor y la falsedad. Ingenuamente se había propuesto destruir fronteras, había querido ser un Don Juan (75), "había querido romper con el mito de que la mujer únicamente ama y su deseo no existe sin el requisito del amor ... sin darme cuenta [nos dice] que luchaba en un campo de batalla donde mi derrota ya estaba prevista" (82).

El texto de Guerra pone en evidencia la compleja dicotomía en que se encuentra "el Otro femenino" frente al problema de la representación de la sexualidad en relación a la búsqueda de la identidad, precisamente porque, en la dialógica interna de lo femenino, como incisivamente Dale M. Bauer ha señalado, se corre el peligro de internalizar "la voz autoritaria del patriarcado". ${ }^{3}$ Si la mujer está ligada a las limitaciones ideológicas de un

\footnotetext{
${ }^{2}$ Las "zonas silenciadas" aludidas por Guerra corresponden a lo que Elaine Showalter denomina el "espacio femenino" y a lo que Hélène Cixous se refiere como "the 'wild zone' or repressed female consciousness". Según Showalter, "through voluntary entry into the wilde zone, other feminist critics tell us [Showalter alude al artículo de Mari McCarthy "Possessing Female Space: 'The Tender Shoot", Women's Studies 8 (1981)], a woman can write her way out of the 'cramped confines of patriarchal space" ["Feminist Criticism in the Wilderness" 263].

${ }^{3}$ La dicotomía psicosocial de los valores morales en la dialógica interna femenina ha sido analizada por Carol Gilligan en su primordial estudio In a Different Voice: Psychological Theory and Women's Development. También cabe mencionar que, en los últimos ańos, ha surgido una crítica considerablemente importante pertinente a los fundamentos patriarcales y su acersión de autoridad objetiva en relación a las premisas éticas y epistemológicas de la tradición cultural de Occidente. Luce Irigaray, Genevieve Lloyd, y Susan Mollin Okin, por ejemplo, han demostrado la naturaleza eminentemente androcéntrica de la filosofía y teoría política occidental en relación a su proyección sobre el sujeto u "Otro femenino". Dale M. Bauer, por consiguiente, en su libro Feminist Dialogics: $A$ Theory of Failed Community, concluye que, "we must struggle to refashion inherited social discourses into words which rearticulate intentions (here feminist ones) other than normative or disciplinary ones" (2).
} 
discurso patriarcal que no le ha asignado una posición igualitaria ¿de qué modo podrá el sujeto femenino definirse desde un espacio fuera del orden simbólico dominante?

Adecuando al contexto latinoamericano los postulados de la corriente feminista francesa, la redefinición ontológica de la mujer como actante político y social es, para Guerra, la vía de acceso a la verdadera identidad. Esto se pone en evidencia al final de la novela en el que "ese cuerpo trasciende su economía exclusivamente libidinal para ser un cuerpo político". 4 Con esto en mente, la estrategia narrativa en Más allá de las máscaras se centra, al unísono, en la experiencia física de crear un texto - dentro del texto-y en la experiencia psicológica de crear una nueva identidad femenina "desde su propio centro" histórico. Guerra explícitamente delinea el surgimiento, de esta voz fidedigna a través de la amistad de la protagonista con Aurora, nombre por lo demás simbólico de un nuevo amanecer. La conocí - nos dice Cristina - "un asoleado día de primavera en los jardínes del Congreso [cuando] dirigía una huelga de hambre en apoyo del conflicto laboral de los mineros" (97). "A través de Aurora fui penetrando en un mundo que apenas vislumbraba. ... empecé a sentir la necesidad de oírla, porque sus palabras fluían para mí en un nuevo amamantar" (102-3). Guiada por su espíritu de lucha por una causa social, por el valor y la autenticidad de esta mujer obrera, Cristina la escritora/heroína, encuentra su propio espacio, sus propios valores y, finalmente, su autonomía.

La destrucción de Ariadna, simbólicamente el modelo femenino asignado por la sociedad a Cristina, es el primer paso hacia esta transformación. El destrozo de la muñeca, es una escena recurrente en la literatura femenina. Desde $A$ Doll's House de Ibsen, a la "La muñeca menor" de Rosario Ferré así lo atestiguan. Tanto allí como aquí, el hacerla añicos simbólicamente alude no sólo a la deconstrucción del proceso de objetificación/ abyección de la mujer, sino también a la toma de conciencia de su propia madurez emocional. Sin embargo, debo agregar, que en el caso del cuento de Ferré, ésta subvierte su signo convencional de femineidad, en su significado de pasividad u ornamentación, para convertirse en un objeto ritual mágico de poder ya que, si bien recordamos, en la versión puertorriqueña la muñeca, alegóricamente, destruye la larga historia de abuso masculino, cuando de sus ojos salen las destructivas "chácharas" liberadoras.

Respecto al sentido de comunidad de la experiencia femenina más allá de las fronteras de lo personal, la novela conlleva un mensaje de solidaridad sociopolítica, que recuerda La casa de los espiritus 1982 de Isabel Allende. Cristina, lo mismo que Alba, apoyada por el valor de otras mujeres y unidas todas por una causa común, trasciende, a través de la escritura, su propia tragedia personal (los horrores y violaciones del campo de concentración en el caso de Alba, la desilusión amorosa y deterioro espiritual en el caso de Cristina) dando cabida a un espacio de envergadura mucho más significativa y universal: el de su inserción en la historia. "Escriba señorita, escriba mucho" fueron las últimas palabras de Aurora antes de ser acribillada a balazos. Y así lo hice, nos dice Cristina:

\footnotetext{
${ }^{4}$ La participación política de las mujeres en el devenir histórico de Latinoamérica es de larga trayectoria. Su compromiso político desde las guerras por la Independencia hasta nuestros días, con su participación en movimientos de resistencia contra las dictaduras, así lo atestiguan. En Chile, Argentina, El Salvador y, recientemente, en Nicaragua, numerosísimos son los ejemplos de mujeres que se arriesgaron y murieron defendiendo una causa.
} 
Basándome en las conversaciones con Aurora fui sacando artículos sobre las condiciones de vida en el mineral, la dieta alimenticia de los ninos, los últimos accidentes y los abusos del sistema de pulpería (104).

Escribía con entusiasmo, como Eva en Eva Luna (Allende 1987), quien, ante la vista de lo que pasaba en Venezuela decidió, no tan sólo participar en la fuga de los guerrilleros detenidos en el Penal de Santa María (ayudando con la fabricación de la masa de pan que cubría las granadas liberadoras) sino que introdujo la guerrilla y el asalto (271-2) como también la figura del General Tolomeo Rodríguez (275) en el libreto de su telenovela "Bolero". La intención de Allende es clara. Mofándose de las autoridades y exponiendo el falso orgullo del honor militar, su telenovela se convierte en testimonio;' testimonio, como explica Eva, "de las cosas que pasan y de otras que pasaron antes de que yo naciera" (276), "sintiéndome una mujer astuta por mis estrategias que lograban burlar la censura del gobierno" (104), nos dirá Cristina, en Más allá de las máscaras.

Esta estrategia narrativa se podría interpretar como la versión literaria del discurso de la "ética de la solidaridad" descrito en términos socio-ideológicos por Nancy Fraser. ${ }^{6}$ Aplicado este discurso al metatexto de Allende y Guerra, Alba, Eva y Cristina, en su calidad de amanuenses al ser las portavoces de las experiencias de tantas mujeres latinoamericanas divididas por clase y situación económica, pero, como ellas, oprimidas por un sistema cultural patriarcal, en su esfuerzo por transformar y redefinir el discurso social heredado, rearticulan uno cimentado en una "identidad política feminista colectiva".

Frutos extraños, la reciente colección de cuentos de Guerra, precisamente no podría leerse de otra manera. Sin embargo el contexto micropolítico colectivo del discurso se torna agresivo, teñido de un hondo matiz denunciatorio haciéndonos tomar conciencia de las diversas formas de opresión y violencia de que es víctima la mujer marginalizada, desposeída y explotada. A los temas peculiares empleados en su novela, Guerra añade en "Rehenes de oscuros atavíos" el de la activa participación política de la mujer que, como tantas, arriesgaron sus vidas por la causa socialista en Chile. La crueldad física y psicológica vinculada a las diversas formas de tortura a que fueron sometidas en los días que siguieron al golpe militar y la caída de Allende, son ejemplos fehacientes de la violencia que la sociedad olvida, fácilmente, para no asumir responsabilidad. En otros cuentos, "Melodía trunca del Oeste" y "Travesías" por ejemplo, aparece como constante el tema de la mujer itinerante que viaja a California en busca de trabajo, en el caso de la campesina mexicana o de las imágenes mitificadas por la televisión de California como "la tierra del oro y de las estrellas rutilantes" para encontrar sólo la explotación, perversión y finalmente la muerte.

\footnotetext{
${ }^{5}$ Para una discusión crítica sobre el sentido de solidaridad socio-histórico de la experiencia femenina en esta novela, además de su relación con la picaresca como técnica narrativa, véase mi reciente artículo: "El sabor picaresco en Eva Luna".

${ }^{6}$ Nancy Frazer en su artículo "Towards a Discourse Ethic of Solidarity" define el discurso de la ética de la solidaridad como uno "grounded in a collective feminist political identity, which is to be struggled for rather than simply being given through the fact of femininity and which draws on culturally specific vocabularies, interpretative resources, and forms of life in the construction of oppositional consciousness" (426). Esta estrategia de apoyo mutuo es, para Hilary Rose, "el único medio de superar la alienación femenina en un mundo social de dominación masculina" (89).
} 
En ambos casos Guerra se apropia del mito del paraíso o espacio utópico en la tradición masculina. Como se observa en "Travesías", el contraste entre lo imaginado y la realidad adquiere una nota de terrible amargura: "Al año de su estadía, ella comprendió que California también era el territorio de los paraísos irremisiblemente perdidos" (20). El peregrinaje de estas protagonistas está postulado desde una perspectiva femenina en la cual la mujer, lejos de ser la causante de la caída o el pecado original, es una víctima de la degradación producida por el interés monetario, la comercialización u objetificación de las relaciones humanas y los avances de la tecnología. En el caso de "Travesías" la protagonista, lejos de convertirse en la imagen visual de la mujer sofisticada, termina de mesera en un restaurante barato. Su única alternativa fue sumergirse en la multitud sin identidad y sin imagen en ninguna película ni en ningún programa de televisión (21). Las imágenes entregadas por los medios de comunicación de masa poseen un contrasello en la realidad que se presenta como fragmentada y distorsionada por estas imágenes. Del mismo modo como ella se viste con aquel traje que la hace parecerse a Marilyn Monroe, el hombre que ha trabajado en la casa de muñecas de Disneylandia le adscribe, a ella, la calidad de objeto, de muñeca que cambia su identidad. Así puede ser árabe, esquimal o hawaiana nada más que por el traje. De allí que la violación y el consecuente asesinato de la protagonista deja un sabor amargo y una sensación que raya en lo grotesco.

Respecto a la relación entre discurso femenino y las estructuras de poder, en otro de sus cuentos, "De brujas y de mártires", las contingencias históricas del presente se remontan a su contexto de la Conquista de América en el que el problema de raza y sexo se relaciona con el de la estructura opresor/oprimido expresándose de manera homóloga en las relaciones hombre-mujer. De este modo, el espacio que la protagonista india comparte con nosotros es el de la memoria del ultraje y la violencia cometidos por el conquistador a la tierra de sus antepasados (Guatemala), a sus tradiciones y a su raza indígena. En el momento en que la protagonista es violada por el conquistador español, se dice: "Indefensa vuelve la cabeza y divisa los ojos lujuriosos del enemigo, de ese hombre cubierto de sudor que se empeñó en invadir su patria y ahora se empeña en poseer su cuerpo" (33). Reviviendo la escena de siglos, "ella indecisa buscó a su madre y, entre los ojos atemorizados de las otras mujeres, vio los de ella velados por el odio y la tristeza" (35). Guerra revela, con un nuevo lenguaje directo, violento y, a veces descarnado, los horrores del racismo. En la valorización que se hace del "Otro", la mujer no es otra cosa que el fetiche sexual, objeto del deseo, algo superficial, lascivo, pero expresado en el más alto grado de cosificación y despreciabilidad.

Otras formas de alienación y de violencia rozan en lo patético y lo truculento y acentúan el agobiante sentimiento de degradación de la mujer en un mundo deshumanizado. Tal es el caso de "Frutos extraños", el cuento más largo y el que le da el título a la colección. Guerra, rebasando las fronteras geográficas, nos recrea la historia con mayúscula de las injusticias y violaciones perpetradas a la raza negra en los Estados Unidos. El cuento se mueve libremente a través del tiempo y del espacio, yuxtaponiendo la institución de la temprana esclavitud con las múltiples subsiguientes injusticias del presente: explotación sexual, segregación racial, manifiesta discriminación social y económica (82).

$\mathrm{Ni}$ aceptada dentro del grupo racial blanco, ni capaz de construir su identidad fuera de él, la protagonista (que por las fechas 1915-1959 y las coincidencias biográficas es Billie 
Holliday) ${ }^{7}$ trata de romper la norma de las barreras ideológicas (clase, color y raza) creando su identidad a través de su arte: como cantante de jazz, "donde no existían las lianas de la desigualdad": "[donde] ella y sus compañeros eran los únicos talladores de su propia alegría, los únicos creadores sagrados que usaban el proscenio como trampolín de mil mundos imaginados. [Porque] cuando ellos interpretaban una melodía, también sentían que, por fin, eran capaces de borrar toda obligación de escuchar a los blancos, porque los blancos debían callar para escucharlos a ellos" (90). Deslumbrada por su éxito artístico, "The Lady of the Blues que todos, blancos y negros, admiraban", piensa, ingenuamente, que su arte será la clave para "debilitar los prejuicios" y ser finalmente aceptada, visión utópica que contrasta arduamente con la triste realidad. Nunca supo, con certeza, cuándo empezaron "a gestarse los frutos extraños del resentimiento", pero sí sabe que "anidada en el regazo fosforecente de la heroína, ella se convirtió en una extraña bailarina que danzaba aprisionada en el claustro de un círculo de fuego blanco" (103). También sabe que "se inyectaba porque le resultaba absolutamente insoportable el acoso de tanta injusticia en el único reino posible de este mundo" (104).

Un agobiante clima de cuestionamiento, oposición, ruptura y deseo de cambio irrumpe de los cuentos de Frutos extraños. La multiplicidad de contradicciones sociales, construye la imagen de una humanidad negada, silenciada, al mismo tiempo que permeabiliza el malestar de un sistema social en crisis. El discurso fundamentado en la imagen poética nos perturba e inquieta por su pluralidad connotativa. ¿Qué intenta sugerir? ¿ira o compasión? ¿furia o desilusión por ser la mujer tan ingenua y creer en la posibilidad de justicia? o ¿es más bien un medio para llevar a otras metas?

Sin duda, los cuentos y la novela son herramientas para problematizar y cuestionar en el que "la mirada del Otro en lo Otro ha resultado fuente prolífera para la inscripción de un contradiscurso" (Guerra 153). Un contradiscurso polifónico y multifocal caracterizado por un compromiso socio-político y altamente transgresivo respecto a los cánones con que la sociedad patriarcal estructura y delimita el ser y el quehacer femeninos. Fruto de una reflexión personal y de un quehacer vinculados al problema de la mujer y sociedad se impone como un proyecto ideológico de cambio y apertura. Como sujeto hablante se torna, heterogéneo y desbaratador, metáfora de la diferencia.

El análisis crítico nos fuerza a intervenir. Frutos extraños y Más allá de las máscaras cumple esta función. Promover la conciencia social es esencial para develar y liberarse de las ataduras impuestas por las convenciones socio-culturales, para ver el mundo en toda su belleza, para participar y hacer la diferencia. No ya más Ariadnas "de labios cuidadosamente delineados que jamás se abren para denunciar una verdad" (Más allá ... 114). Nunca más "atadas a una estaca y con el cuerpo preñado de fantasías" como afirmé al comienzo de este ensayo, sino dueñas de su texto y de su destino.

7 "Strange Fruit" era el título de una de las canciones más famosas de Billie Holliday (nota del editor). 


\section{Obras Citadas}

Allende, Isabel. Eva Luna. Barcelona: Plaza \& Janés, 1987.

Bauer, Dale M. Feminist Dialogics: A Theory of Failed Community. Albany: State University of New York Press, 1988.

Cixous, Hélène and Catherine Clément. The Newly Born Woman. Trans. Betsy Wing. Minneapolis: University of Minnesota Press, 1986.

Felski, Rita. "Feminism, Postmodernism, and the Critique of Modernity", Cultural Critique 13 (Fall 1989), 33-56.

Ferré, Rosario. "La muñeca menor". Río Piedras: Ediciones Huracán, 1980.

Fraser, Nancy. “Towards a Discourse Ethic of Solidarity”, Praxis International 5/4 (1986), 425-29.

Gálvez-Carlisle, Gloria. "El sabor picaresco en Eva Luna". Sonia Riquelme/Edna Aguirre, eds., Critical Approaches to Isabel Allende's Novels. New York: Peter Lang, 1991, 165-177.

Gilligan, Carol. In a Different Voice: Psychological Theory and Women's Development. Cambridge, MA: Harvard University Press, 1982.

Guerra, Lucía. Frutos extraños. Caracas: Monte Ávila, 1991.

Más allá de las máscaras, $2^{\mathrm{a}}$ edición. Santiago, Chile: Editorial Cuarto Propio, 1990.

"Las sombras de la escritura: hacia una teoría de la producción literaria de la mujer latinoamericana", Cultural and Historical Grounding for Hispanic and Luso-Brazilian Feminist Literary Criticism. Ed. Hernán Vidal. (Series Literature and Human Rights 4) Minneapolis: Institute for the Study of Ideologies and Literature, 1989, 129-164.

Rose, Hilary. "Hand, Brain, and Heart: A Feminist Epistemology for the Natural Sciences", Signs 9/1 (1983), 73-90.

Showalter, Elaine. "Feminist Criticism in the Wilderness", Feminist Criticism. Essays on Women, Literature and Theory. Ed. Elaine Showalter. New York: Pantheon Books, 1985, 243-270.

Vega, Ana Lydia. "Pollito/Chicken", Virgenes y Mártires, $2^{\mathrm{a}}$ edición. Río Piedras: Editorial Antillana, 1983, 73-79. 
